\title{
Yapay sinir ağları metodu ile günlük çiğ noktası sıcaklığı tahmini
}

\section{Daily dew point temperature estimation with artificial neural networks method}

\author{
Nazan Sevtap CAN ${ }^{1, a}$, Arzu ŞENCAN ŞAHIN* ${ }^{* 1, b}$ \\ ${ }^{1}$ Isparta Uygulamalı Bilimler Üniversitesi, Teknoloji Fakültesi, Makine Mühendisliği Bölümü, 32200, Isparta
}

• Geliş tarihi / Received: 27.01.2021 • Düzeltilerek geliş tarihi / Received in revised form: $21.07 .2021 \quad$ • Kabul tarihi / Accepted: 30.07 .2021

\begin{abstract}
$\ddot{\mathbf{O} z}$
Çiğ noktası sıcaklığı, tarım başta olmak üzere ekolojik, hidrolojik ve klimatolojik model benzeri birçok faaliyetin belirlenmesinde önemli rol oynamaktadır. Bitkilerin büyüme ve gelişmeleri için çiğ noktası sıcaklığı önemli bir faktördür. Çiğ noktası sıcaklığının yüksek olduğu ve değişkenlik gösterdiği durumda bitkiler olumsuz etkilenmektedir. Bu sebeplerden dolayı seyrek yağış alan kurak bölgelerde ve seracılığın yoğun olduğu bölgelerde çiğ noktası sıcaklığ1 tahmini önemli bir role sahiptir. Bu çalışmada Muğla ili için 1 Ocak 2019 ve 31 Aralık 2019 tarihleri arasındaki bağıl nem oranı, basınç ve hava sıcaklığı verilerine bağlı olarak yapay sinir ağları (YSA) metodu kullanılarak çiğ noktası sıcaklığı tahmin edilmiştir. Bunun için MATLAB programlama dili kullanılmıştır. YSA'nın eğitiminde en iyi sonucu, gizli tabakada 7 nöron sayısıyla Levenberg-Marquardt (LM) algoritması ve ileri beslemeli geri yayılımlı (Feed-Forward BackProp) sinir ağı modeli vermiştir. RMSE hata değeri 2.112987863, $\mathrm{R}^{2}$ değeri 0.887436814, cov değişim katsay1S1 0.170439905 olarak bulunmuştur. Bu değerlerin kabul edilebilir seviyede olduğu ve çiğ noktası sıcaklığının tahmin edilmesinde bu metodun başarılı bir şekilde kullanılabileceği sonucuna varılmıştır. Çiğ noktası sıcaklığı tahmininde yapay sinir ağları modelinin farklı bölgeler ve farklı meteorolojik parametreler için de kullanılabilmesi mümkündür. Bu tahminler, özellikle tarımla uğraşanlar için oldukça yararlı olacaktır.
\end{abstract}

Anahtar kelimeler: Çiğ noktası sıcaklı̆̆ı, Matlab, Yapay sinir ağları

\begin{abstract}
Dew point temperature plays a significant role in determining many activities such as ecological, hydrological, and climatological models, especially agriculture. Dew point is an important factor for the growth and development of plants. Plants are negatively affected when the dew point temperature is high and varies. For these reasons, the dew point temperature prediction has become important in arid regions with sparse rainfall and in areas where greenhouse cultivation is intense. In this study, the artificial neural network (ANN) method was used to estimate the dew point temperature in Mugla Province based on relative humidity, pressure and temperature data from January 1, 2019 to December 31, 2019. The MATLAB programming language is used for this. The Levenberg-Marquardt (LM) algorithm and the Feed-Forward Back Propagation neural network model give the best results in ANN training, where there are 7 neurons in the hidden layer. The RMSE error value is 2.112987863 , the $R^{2}$ value is 0.887436814 , and the cov coefficient of variation is 0.170439905 . These values have been found to be at acceptable levels, and this method can be successfully used to estimate the dew point temperature. The artificial neural network model can be used to estimate the dew point temperature for different regions and different meteorological parameters. These estimates will be very helpful, especially for those engaged in agriculture.
\end{abstract}

Keywords: Dew point temperature, Matlab, Artificial neural networks

\footnotetext{
*b Arzu ŞENCAN ŞAHİN; arzusencan@isparta.edu.tr, Tel: (0246) 21467 72, orcid.org/0000-0001-8519-4788

a orcid.org/ 0000-0003-1002-9109
} 


\section{Giriş}

Çiğ noktası sıcaklığı, hava basıncının sabit kaldığ sürece, havadaki su buharının çiğ veya su damlacıklarına dönüşeceği sıcaklıktır. Kısacası, doygunluk buhar basıncı ve gerçek buhar basıncının eşit olduğu sıcaklık olarak tanımlanabilir. Çiğ noktası, bağıl nem ile ilişkilidir. Yüksek bağıl nem, çiğ noktasının mevcut hava sıcaklığına daha yakın olduğunu gösterir. \% 100 bağıl nem, çiğ noktasının mevcut sicaklığa eşit olduğunu ve havanın maksimum su ile doymuş olduğunu gösterir. Çiğ noktası sabit kaldığında ve sıcaklık arttı̆̆ında bağıl nem azalır. Günümüzde çiğ noktası sıcaklıkları hazırlanmış tablolardan bağıl nem ve sicaklığa bağlı olarak belirlenmektedir (Zounemat-Kermani, 2012).

Hava tahmini birçok alan için önemlidir. $\mathrm{Bu}$ alanlardan bazıları tarım, ulaşım, havayolu taşımacılığı olarak siralanabilir. Anlık hava durumlarının rapor edilmesi kolaydır ancak geleceğe yönelik hava durumlarının tahmini, analizi oldukça zordur ve önemlidir. Tarım, hava ve yağışlara endeksli olan temel alanlardan biri olup hava durumu raporları sayesinde tarımda zarara uğrayan alanlar gittikçe azalmaktadır. Hava durumu raporu kullanıciların bilgilendirilmesi içindir. Bu sebeple, hava durumu tahmininin en az hata ile belirlenmesi kullanıcılar için yararlı olacaktır. Geleceğe yönelik hava tahminleri için birçok yöntem bulunmaktadır. Ancak en iyi sonuç, en uygun yöntemin kullanılması ile elde edilecektir (Sankari ve Valarmathi, 2017).

Sıcaklık, bitkilerin büyüme ve gelişmeleri için oldukça etkilidir. Her bitkinin yetişmesi için optimum sıcaklık değerlerine ihtiyaç duyulmaktadır. Yüksek sicaklıktan bitkiler etkilenmektedir. $\mathrm{Bu}$ amaçla ilk kez ABD'de sıcaklığa dayalı bölge haritaları çalışmalarına Amerikan Bahçe Bitkileri Derneğinin 1974-1995 yılları ait 4745 meteoroloji ölçüm merkezinden aldığı veriler kullanılarak başlanmıştır (Paulsen, 1994; Peşkircioğlu vd., 2016). Seralarda ürün yetiştirme sürecinde yetiştirilecek olan bitkiler için gerekli olan 1ş1k, nem, sıcaklık vb. gibi unsurların kontrolü sağlanabilir. Seralarda yetişen bitkiler büyüme sırasında farklı sıcaklıklara gereksinim duymaktadır. Sıcaklık değerlerinin değişkenlik göstermesi, bitkinin verimini ve kalitesini etkilemektedir. Özellikle Akdeniz iklimine sahip bölgelerde yaz aylarında sıcaklığın yüksek değerlere ulaşması sera ürünlerinin veriminin ve kalitesinin düşmesine yol açmaktadır. Sicaklığın kontrolünün sağlanmasında iklimlendirme, havalandırma ve soğutma gibi yöntemler kullanılmaktadır (Boyacı vd., 2017).

Birçok tarımsal, ekolojik, hidrolojik ve klimatolojik model için çiğ noktası sıcaklığı gereklidir (Hubbard vd., 2003). Özellikle seyrek yağış alan kurak bölgelerde çiğ noktası sıcaklığının bilinmesi, bitkilerin bir zarara uğramaması ve verimli olabilmesi için gereklidir (Agam ve Berliner, 2006). Seralarda da çiğlenme önemli bir sorundur. Sera dışında havanın günlük ortalama çiğ noktası sıcaklığı daha düşük olurken, bu değer sera içinde daha yüksek olabilir. Çiğlenme olayı genellikle gece ortaya çıkmaktadır. Bu nedenle, gece sera içinde belirlenen çiğ noktası sıcaklığı değerinden yararlanılabilir. Çiğ noktası sıcaklığının tahmin edilmesiyle seralar için gerekli önlemlerin önceden alınması sağlanacaktır.

Yapay zeka yöntemlerinden biri olan yapay sinir ağları (YSA) metodu pek çok mühendislik uygulamasında kullanılmaktadır. Akyüz vd. çalışmalarında Antalya ili için aylık ortalama bağıl nem ve buhar basıncı değerlerini kullanılarak YSA metoduyla aylık ortalama hava sıcaklığı değerlerini tahmin etmişlerdir. YSA metodunun ortalama hava sıcaklığ 1 tahmininde başarılı bir şekilde kullanıldığııı ifade etmişlerdir (Akyüz vd., 2020). İlkuçar vd., çalışmalarında YSA metodu ile mekanik özelliklere göre sekiz farklı ağaç türünün tahmini yapmışlardır. İleri beslemeli geri yayılımlı YSA metodunun \%96.29 doğruluk oranında tahmin yapabildiğini göstermişlerdir (İlkuçar vd., 2018). Çiğ noktası sıcaklığının tahmininde de özellikle son zamanlarda yapay zeka yöntemleri kullanılmaktadır. Mehdizadeh vd. çalışmalarında İran'ın kuzeybatısında iki istasyonda çiğlenme noktası sıcaklığını tahmin etmek için gen ifade programlama (GEP) yöntemini kullanılmışlardır (Mehdizadeh vd. 2017). Shank vd. çalışmalarında daha önceki yıllardaki hava durumu verilerini girdi olarak kullanarak daha sonraki yıllardaki çiğ noktası sıcaklığını tahmin etmek için yapay sinir ağlarını (YSA) kullanmışlardır (Shank vd., 2008). Baghban vd. çalışmalarında nöro bulanık çıkarım sistemi (ANFIS) ve genetik algoritma (GA) yöntemlerini kullanarak çiğ noktası sıcaklı̆̆ tahmini yapmışlardır. Korelasyon katsayısı değerleri 0.9987 olarak bulunmuştur (Baghban vd., 2016). Mohammadi vd. çalışmalarında günlük olarak çiğ noktası sıcaklığını tahmin etmek için yapay sinir ağları metodunu kullanmışlardır. Korelasyon katsayısı değerleri 0.9617 olarak bulunmuştur (Mohammadi vd., 2015). Naganna vd çalışmalarında hibrit yapay zeka yöntemleri (YSA ve ateş böceği algoritması) kullanarak Hindistan'da iki bölge için çiğ noktası sıcaklığ 1 
değerlerini tahmin etmişlerdir (Naganna vd., 2019). Qasem vd. çalışmalarında GEP, M5 model ağacı (M5) ve Destek Vektör Regresyon (SVR) yöntemlerini kullanarak İran'da Tebriz bölgesi için meteorolojik parametrelere bağlı olarak çiğ noktası sıcaklığ 1 değerlerini tahmin etmişlerdir (Qasem vd., 2019). Amirmojahedi vd. çalışmalarında İran'ın güney kıyı kesiminde yer alan Bandar Abass limanı için günlük çiğ noktası sıcaklığını tahmin etmek için aşırı öğrenme makinesi (ELM) ile dalgacık dönüşümü (WT) algoritmasını birleştiren yeni bir hibrit yaklaşım kullanmışlardır (Amirmojahedi vd., 2016). Alizamir vd. çalışmalarında aşırı öğrenme makinesi (ELM) ve regresyon ağacı (RT) gibi farklı modellerle Kore'de Seul ve Incheon istasyonları için farklı meteorolojik değişkenler kullanarak çiğ noktası sıcaklığını tahmin etmişlerdir (Alizamir vd., 2020). Shiri vd. çalışmalarında YSA ve GEP yöntemlerini kullanarak Kore'de Seul ve Incheon istasyonları için günlük çiğ noktası sıcaklığını tahmin etmişlerdir (Shiri vd., 2014). Kisi vd. çalışmalarında nöro bulanık çıkarım sistemi (ANFIS) ve YSA yöntemlerini kullanarak Kore'de Daego, Pohang ve Ulsan bölgeleri için günlük çiğ noktası sıcaklığı değerlerini tahmin etmişlerdir. Çalışma sonunda her iki yöntemin de aynı doğrulukta performans gösterdiğini ifade etmişlerdir (Kisi vd., 2013). Zounemat-Kermani çalışmasında saatlik çiğlenme noktası sıcaklığını tahmin etmek için çoklu doğrusal regresyon (MLR) ve Levenberg-Marquardt (LM) ileri beslemeli yapay sinir ağı modelinin kullanılabilirliğini incelemiştir (Zounemat-Kermani, 2012). Mohammadi vd. çalışmalarında günlük çiğ noktası sicaklığının tahminde en önemli parametreleri belirlemeye yönelik bir yaklaşım sunmak için uyarlanabilir nöro bulanık çıkarım sistemi (ANFIS) kullanmıştır (Mohammadi vd., 2016).

Çiğ noktası sıcaklığı, gerçek buhar basıncını hesaplamak veya bağıl nemi tahmin etmek için de kullanılabilir (Mahmood ve Hubbard, 2005). Nemli havanın termodinamik özellikleri iterasyona gerek kalmadan kuru termometre sicaklığı ve bağıl nem girdi alınarak, su buharının doyma ve kısmi basınçları ile yaş termometre ve çi ̌̆ noktası sıcaklıkları da bulunabilir. Özbek çalışmasında kuru termometre sicaklığ1 ve bağıl nemin bir fonksiyonu olarak su buharı basınçları, yaş termometre ve çiğ noktası sıcaklıkları gibi nemli havanın termodinamik özelliklerini belirlemek için yapay sinir ağları metodunu kullanmıştır (Özbek, 2016).

Literatür çalışmalarından görüldüğü gibi yapay zeka yöntemleri özellikle son zamanlarda çiğ noktası sıcaklığının tahmininde oldukça yaygın olarak kullanılmaktadır. Bu çalışmada, Muğgla ili için Meteoroloji Genel Müdürlüğü'nden (MGM, 2020) temin edilen önceki hava durumu verileri girdi olarak kullanarak çiğ noktası sıcaklığ tahmin edilmiştir. Çalışma, Matlab programı kullanılarak yapay sinir ağ metoduyla yapılmıştır. Bu metotta nem oranı, basınç, sıcaklık değerlerine bağlı olarak çiğ noktası sıcaklığ 1 tahmin edilmiştir. $\mathrm{Bu}$ çalışmadan elde edilen sonuçlar, Muğla ilinde seracılık için çiğlenmeyi önlemek ve bitki verimliliğini arttırmak için kullanılabilir.

\section{Materyal ve metot}

\subsection{Yapay sinir ăgları}

Yapay sinir ağları (YSA), insan beyninde bulunan biyolojik nöronları taklit eden yazılım tabanlı sentetik yapılardır. YSA özellikle eksik, belirsiz, karmaşık ve bulanık bilgileri işlemekteki başarıları nedeniyle, birçok endüstriyel probleme uygulanabilmektedir. Yapilardaki paralellikten dolayı çok hızlı çalışabilmeleri, onların özellikle gerçek zamanlı olaylarda çalışmalarını sağlamaktadır (Bayır, 2008).

YSA yapay zekâ yöntemlerinden biridir. En basit şekilde ifade edilecek olursa basit biyolojik sinir sistemlerin çalışma şekillerinin taklit edilerek oluşturulduğu matematiksel bir modeldir. YSA temel prensipleri arasında beynin öğrenerek yeni bilgiler elde etme, güçlü düşünme, problem çözme, tahmin etme vb. yeteneklerin kazandırılması gibi özellikler yer almaktadır. Doğrusal olsun ya da olmasın herhangi bir olayla ilgili girdi ve çıtı arasında ilişkiyi, eldeki örneklerden öğrenerek önceki zamanlarda görülmemiş olayları, daha önceki örnekler vasıtasıyla ilişkilendirerek çözüm üretme gibi özellikleri nedeniyle YSA araştırmacılar tarafindan ilgi görmektedir (Kaftan, 2010).

Girdi tabakasından gelen bilgiler belli standartlar çerçevesinde işlenerek çıkış tabakasına iletilir. Ağın temel görevini gizli katman yapmakta ve gizli katman sayısı gerçekleştirilecek amaç doğrultusunda ağdan ağa değişkenlik göstermektedir. Çıkış tabakasında ise ara katmandan gelen bilgiler işlenir ve girdi katmanına sunulmuş olan girdilere göre üretilmesi gereken çıktı üretilir. Ağa sunulan her bir verinin çıkış sayısı kadar çıktı katmanında nöron bulunur. Çıkış katmanından üretilen değerler yapay sinir ağlarının probleme karşı oluşturduğu çıkış değerlerini oluşturmaktadır. Yapay sinir ağları yönteminin kullanıldığ 
problemin en iyi çözümü için kullanılacak gizli katman sayısı ile birlikte katmanlardaki nöron sayılarının belirlenmesi oldukça önemlidir (Şahan ve Okur, 2016).
Şekil 1'de üç ana katmandan oluşan yapay sinir ağı bağlantıları verilmiştir (Ayvaz, 2012).

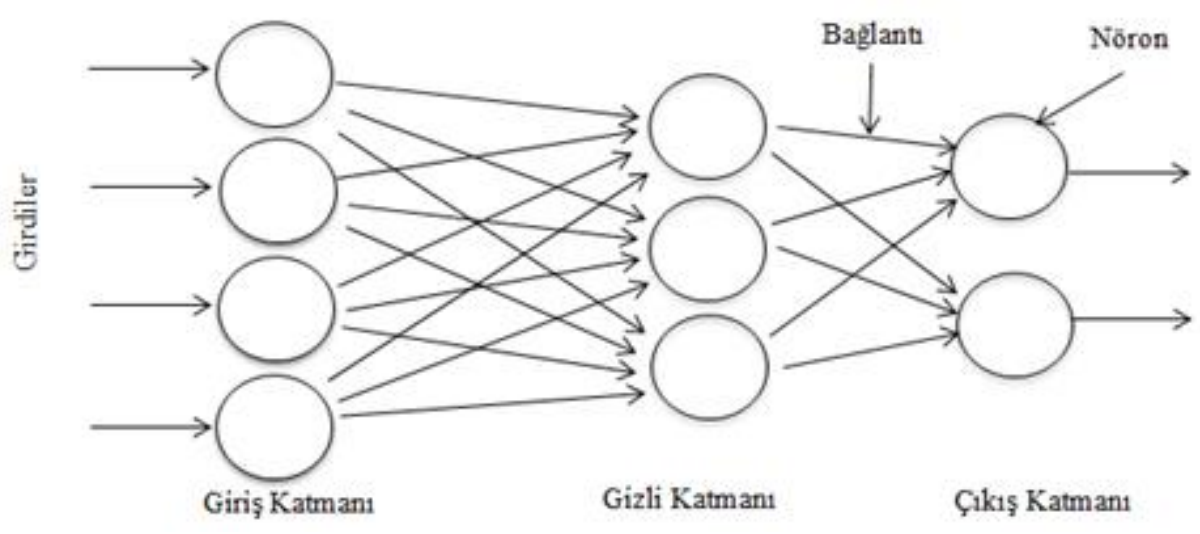

Şekil 1. Yapay sinir ağı bağlantıları

YSA, Şekil 2'de gösterildiği gibi girdi $\left(\mathrm{x}_{\mathrm{i}}\right)$, ağılık $\left(\mathrm{w}_{\mathrm{i}}\right)$, toplama ve aktivasyon fonksiyonu ile çıktı olmak üzere beş temel yapıdan oluşmaktadır (Aslay ve Özen, 2012).

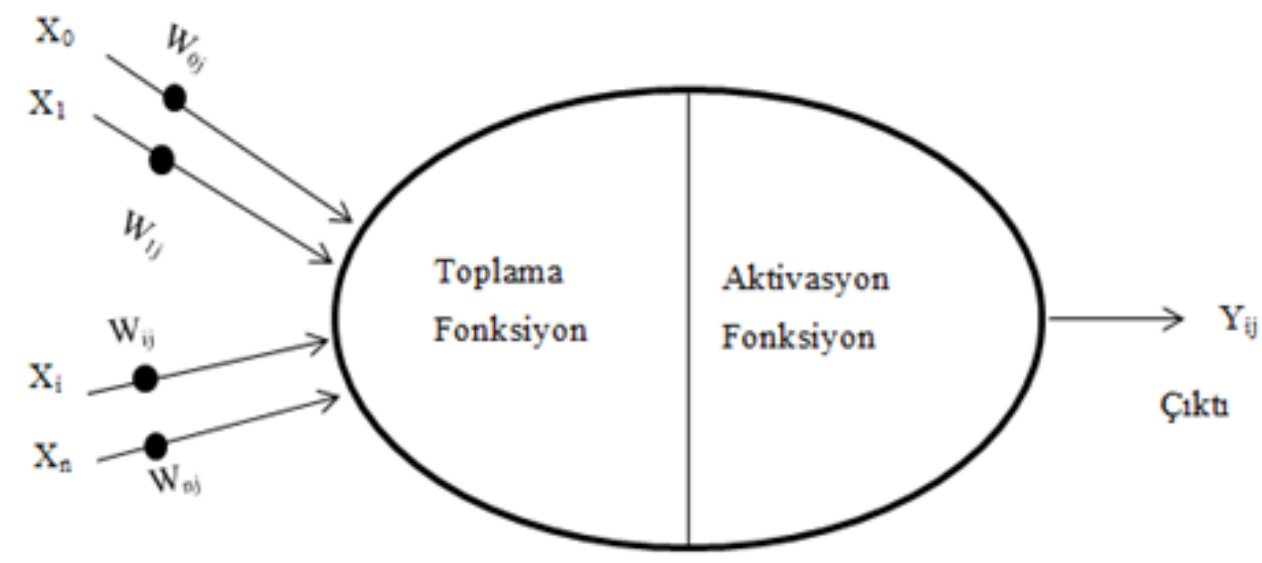

Şekil 2. Yapay sinir ağı hücresinin genel yapısı

\subsection{YSA modeli uygulamasl}

Bu çalışmada; bağıl nem (\%), basınç (mb) ve hava sıcaklığ $1\left({ }^{\circ} \mathrm{C}\right)$ parametrelerine bağlı olarak çiğ noktasi sicaklığ $\left.1{ }^{\circ} \mathrm{C}\right)$ YSA modeli yardımıyla tahmin edilmiştir. Bu parametrelerin çiğ noktası sicaklığını tahmin etmede etkili olduğu bilinmektedir. Şekil 3' de tasarlanan YSA modelinin diyagramı görülmektedir.

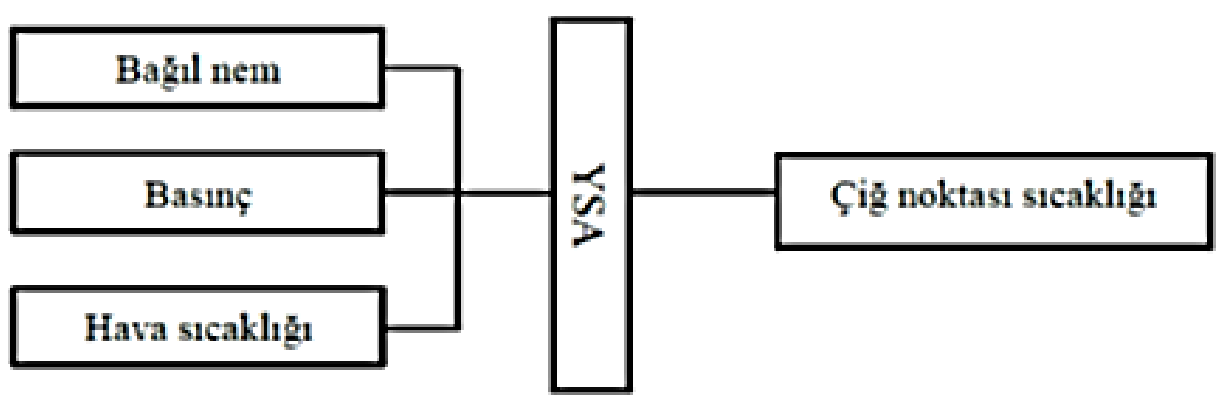

Şekil 3. Tasarlanan sistem için YSA diyagramı 
$\mathrm{Bu}$ parametrelerle ilgili veriler 2019 yılında Muğla ili için günlük olarak hazırlanmış ve verilerin 292 adedi eğitim, 73 adedi test verisi olarak kullanılmıştır. YSA'nın eğitimi için ağ tipi olarak ileri beslemeli geri yayılımlı (Feed-Forward BackProp), geriye yayılma algoritmasının Levenberg Marquardt (LM), Logistic Sigmoid (logsig) aktivasyon fonksiyonu ve ağ performans fonksiyonunun değerlendirilmesinde ise ortalama karesel hata (MSE) seçilmiştir. Verilerin eğitiminde, gizli katmanda en uygun sonucu veren 7 nöron sayısı kullanılmıştır.

Şekil 4'de ara yüz nntool tarafindan oluşturulan yapay sinir ağının blok diyagramı görülmektedir.

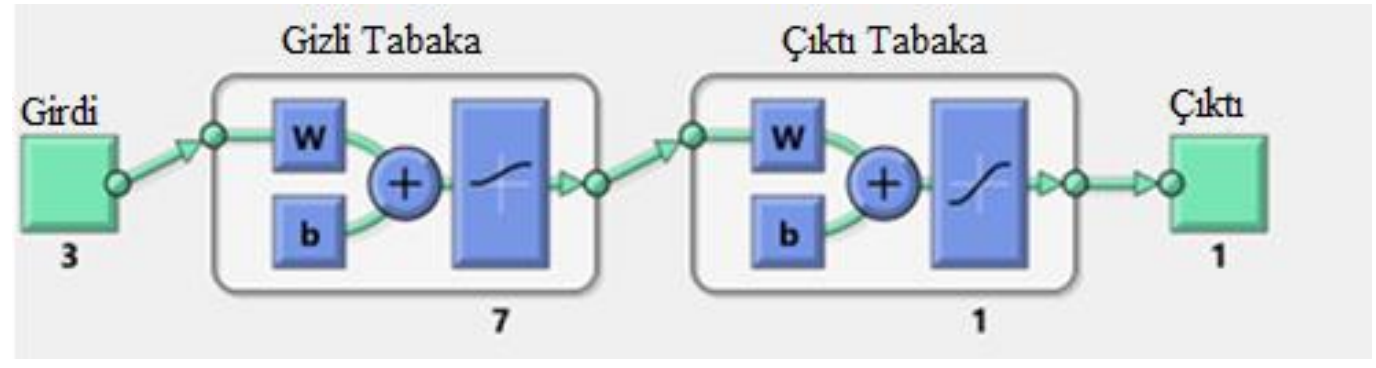

Şekil 4. Ara yüz nntool tarafından oluşturulan yapay sinir ağının blok diyagramı

Veriler YSA modelinde eğitilmeden önce girdi ve çıktı değerleri normalize edilmelidir. Bu çalışmada elde edilen veriler 0 - 1 değerleri arasında normalize edilmiştir. Gerçekleştirilen eğitimde 1000 iterasyon kullanılmıştır. Ağın eğitim süreci 13 iterasyonda tamamlanmış olup ortalama karesel hata (MSE) değerinin en düşük olduğu değere 7. iterasyonda ulaşılmıştır. Şekil 5' de modelin iterasyona bağli performans grafiği görülmekte olup MSE değeri ise 0.0028586 olarak bulunmuştur.

\section{En iyi doğrulama performansı 0,0028586 (7. iterasyon)}

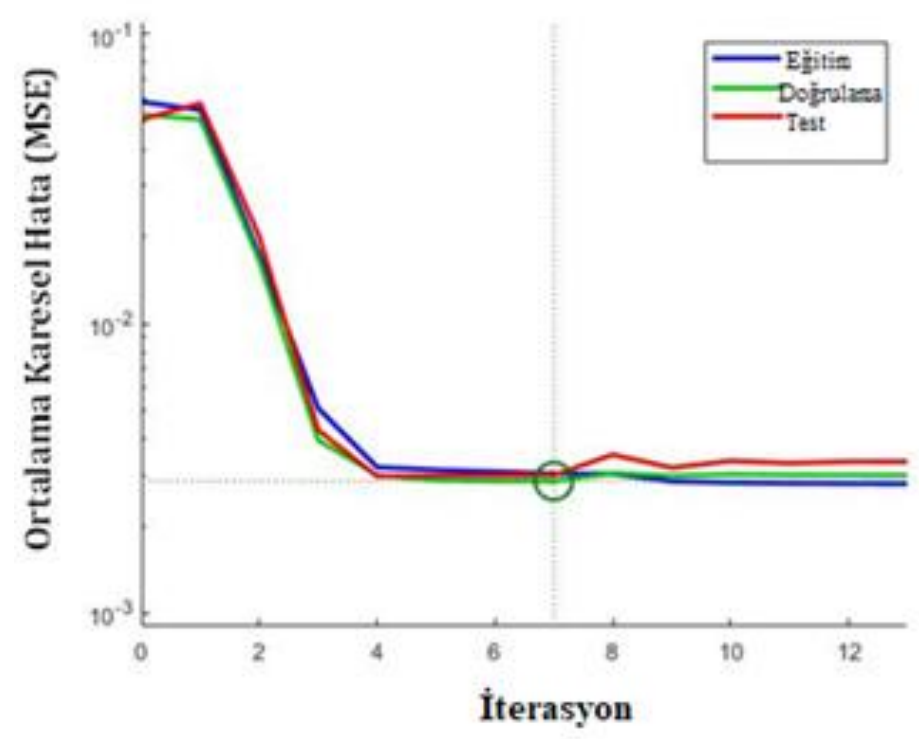

Şekil 5. Eğitim, doğrulama ve test verilerinin performans değişimi

Şekil 6'da modelin performansının gösterildiği korelasyon katsayısı (R) grafikleri verilmiştir. Şekil 6' da korelasyon katsayısı değerlerine bakıldığında eğitim (Training) verileri için $\mathrm{R}=$ 0.957 , test (Test) verileri için $\mathrm{R}=0.9469$, doğrulama (Validation) verileri için $\mathrm{R}=0.94773$ ve Tüm (All) veriler için $\mathrm{R}=0.9547$ olarak bulunmuştur. Tüm veriler için değerlerin 1'e yakın olması, YSA metoduyla elde edilen veriler ile gerçek veriler arasında uyum olduğunu göstermektedir. Korelasyon katsayısı değerlerinin 1'e yakın olması modelin başarılı olduğu anlamına gelmektedir. 
Eğitim: $\mathrm{R}=0.957$

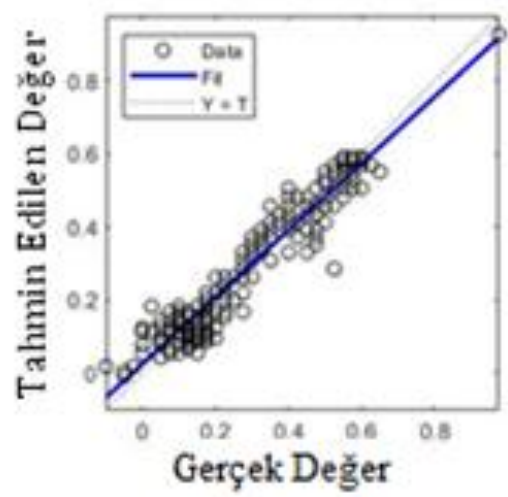

Test: $R=9469$

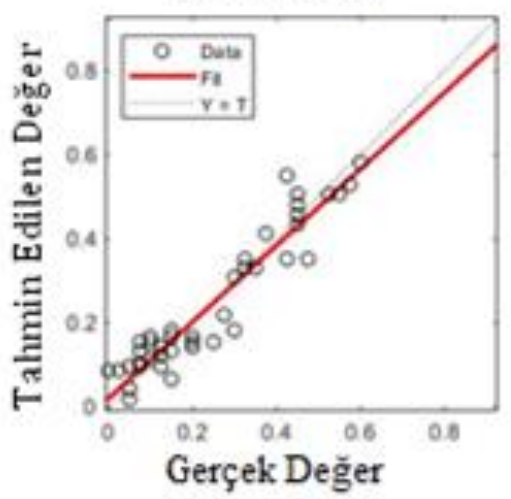

Doğrulama: $R=0.94773$
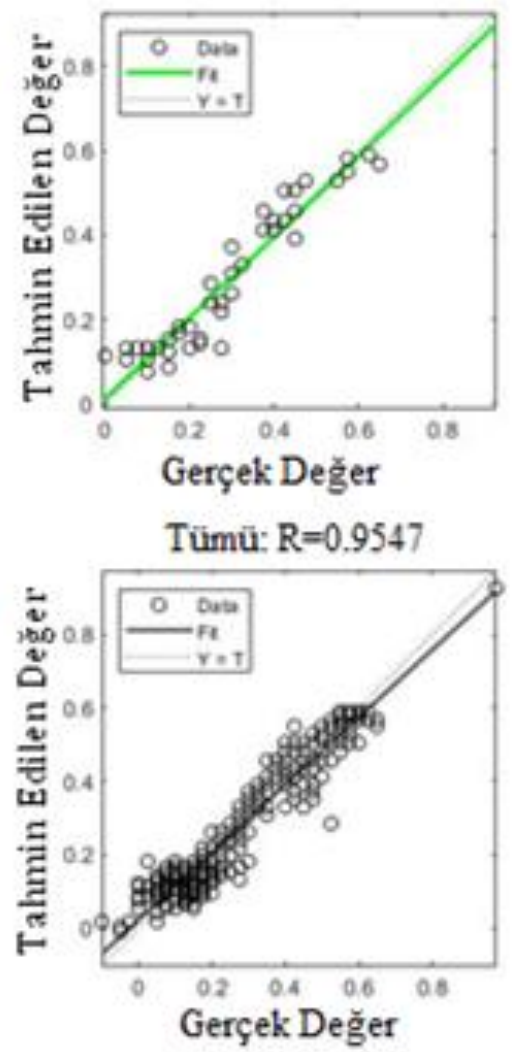

Şekil 6. Eğitim, doğrulama ve test kümelerine ait regresyon grafikleri

YSA modelinin iyi çalışıp çalışmadığını anlamak için ortalama karekök hata (RMSE), korelasyon katsayıs1 $\left(\mathrm{R}^{2}\right)$, varyasyon katsayıs1 (cov) gibi baz1 istatiksel göstergelere bakılmaktadır (Köksal, 2011). $\mathrm{Bu}$ istatistiksel göstergeler aşağıda belirtilen eşitliklerle hesaplanabilir (Şencan ve Kalogirou, 2005).

$R^{2}=1-\frac{\sum_{m=1}^{n}\left(y_{p, m}-t_{m, m}\right)^{2}}{\sum_{m=1}^{n}\left(t_{m, m}-\bar{t}_{m, m}\right)^{2}}$

$R M S E=\sqrt{\frac{\sum_{m=1}^{n}\left(y_{p, m}-t_{m, m}\right)^{2}}{n}}$

$\operatorname{cov}=\frac{R M S E}{\left|\bar{t}_{m, m}\right|} \times 100$

Eşitliklerde belirtilen $\mathrm{y}_{\mathrm{p} . \mathrm{m}}$ tahmin edilen değeri, $\mathrm{t}_{\mathrm{m} . \mathrm{m}}$ gerçek değeri, $\bar{t}_{m . m}$ gerçek değer ortalamasını, $n$ ise veri sayısını ifade etmektedir.

\section{Bulgular}

$\mathrm{Bu}$ çalışmada, YSA modeli ile Muğla ili için farklı meteorolojik değişkenler kullanarak çiğ noktası sıcaklığ 1 tahmin edilmiştir. YSA modelinin oluşturulmasında Matlab programında Neural Network araç kutusu (nntool) kullanılmıştır. Çalışmada, en iyi modeli oluşturmak için farklı algoritma ve nöron sayıları ile denemeler yapılmıştır. Geliştirilen YSA modelinin performansını değerlendirmek için ortalama karekök hata (RMSE), varyasyon katsayısı (cov) ve korelasyon katsayısı $\left(\mathrm{R}^{2}\right)$ göstergeleri kullanılmıştır. $\mathrm{Bu}$ göstergeler yardımıyla günlük çiğ noktası sıcaklığının tahmin edilen değerleri ile ölçülen değerleri arasında istatistiksel bir karşılaştırma yapılmıştır. Elde edilen sonuçlar Tablo 1' de verilmiştir. RMSE ve cov değerlerinin daha küçük değerleri, tahminlerin daha yüksek doğrulukta olduğunu; daha büyük $\mathrm{R}^{2}$ değerleri, tahmin edilen ve ölçülen değerler arasında daha yüksek doğrusal bir ilişkiyi olduğunu gösterir (Mohammadi vd., 2015; Köksal, 2011). Denemeler sonucunda en küçük RMSE ve cov değeri ile en yüksek $\mathrm{R}^{2}$ değerine LM (Levenberg-Marquardt) algoritması ve gizli tabakada 7 nöron sayısıyla ulaşılmıştır. 
Tablo 1. YSA modelinin istatiksel analizi

\begin{tabular}{cccc}
\hline Algoritma-Nöron & RMSE & cov & $\mathbf{R}^{2}$ \\
\hline LM-7 & 2.112987863 & 0.170439905 & 0.887436814 \\
\hline
\end{tabular}

Test veri seti için, günlük olarak ölçülen gerçek çiğ noktası sıcaklığ 1 ve YSA modeli ile tahmin edilen çiğ noktası sıcaklığ1 değerlerinin karşılaştırması Şekil 7' de görülmektedir. Gerçek ve tahmin edilen çiğ noktası sıcaklıkları için $\mathrm{R}^{2}$ değeri 0.9122 olarak bulunmuştur. Yüksek $\mathrm{R}^{2}$ değeri, YSA modeli ile tahmin edilen çĭ̆ noktası sıcaklığı değerleriyle gerçek çiğ noktası sıcaklığı değerleri arasındaki ilişkinin doğruluğunu göstermektedir.

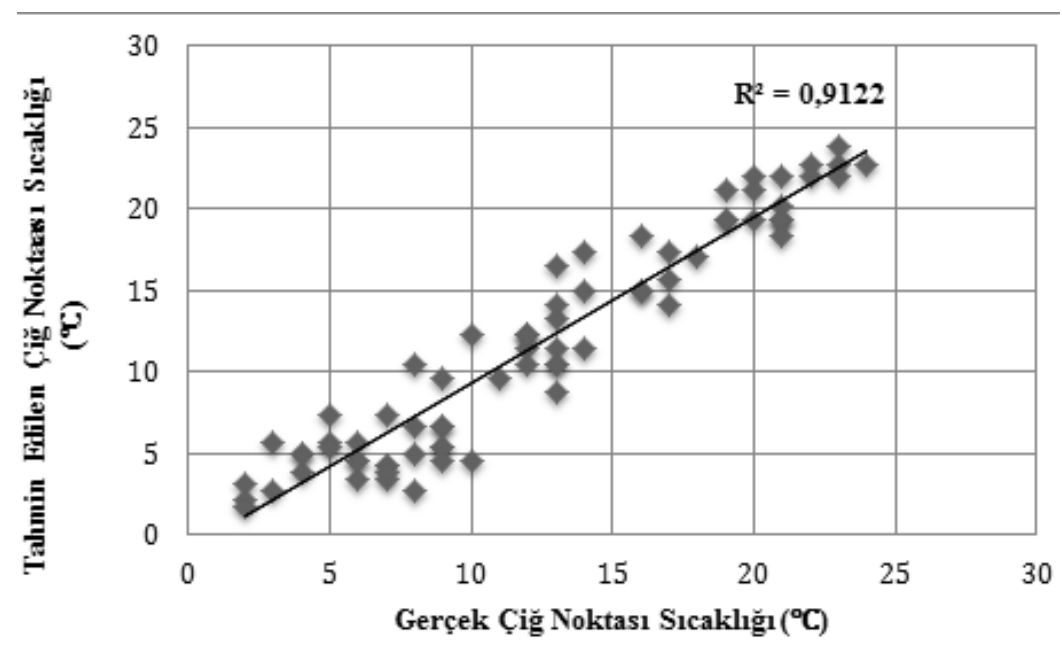

Şekil 7. Gerçek ve tahmin edilen çiğ noktası sıcaklık değerlerinin karşılaştırması

Tablo 2'de Muğla ilinin 2019 yılına ait tüm verileri içinde rastgele alınan günlük nem oranı, basınç ve hava sicaklı̆̆ 1 değerlerine bağlı olarak gerçek çiğ noktası sicaklığı değerleri ve YSA metodu ile tahmin edilen çiğ noktası sicaklı̆̆ değerlerinin karşılaştırılması, hata ve yüzde hata değerleri verilmiştir. Tablo 2' de verildiği gibi en büyük yüzde hata değeri \% 3.8 olarak bulunmuş olup bu hata değerlerinin kabul edilebilir düzeyde olduğu görülmektedir.

Tablo 2. Gerçek ve YSA ile tahmin edilen çiğ noktası sıcaklık değerlerinin karşılaştırması ve hata değerleri

\begin{tabular}{lllllll}
\hline $\begin{array}{l}\text { Nem oranı } \\
(\%)\end{array}$ & $\begin{array}{l}\text { Basınç } \\
(\mathbf{m b})\end{array}$ & $\begin{array}{l}\text { Hava } \\
\text { sicaklı̆̆ı } \\
\left({ }^{\circ} \mathbf{C}\right)\end{array}$ & $\begin{array}{l}\text { Gerçek çĭg noktası YSA ile tahmin } \\
\text { sicaklığı }\left({ }^{\circ} \mathbf{C}\right)\end{array}$ & $\begin{array}{l}\text { Hata } \\
\text { edilen çĭg noktası } \\
\text { sicaklı̆̆ }\left({ }^{(} \mathbf{C}\right)\end{array}$ & & $\begin{array}{l}\text { Yüzde hata } \\
(\%)\end{array}$ \\
\hline 27.5 & 20 & 11 & 4 & 3.847874 & 0.152126 & 3.803159 \\
62.5 & 34 & 25 & 12 & 12.34204 & -0.34204 & 2.8503 \\
65 & 35 & 26 & 13 & 13.22573 & -0.22573 & 1.73639 \\
85 & 43 & 34 & 21 & 20.23069 & 0.769307 & 3.663366 \\
77.5 & 40 & 31 & 17 & 17.36418 & -0.36418 & 2.14221 \\
82.5 & 42 & 33 & 19 & 19.24964 & -0.24964 & 1.3139 \\
82.5 & 42 & 33 & 19 & 19.24964 & -0.24964 & 1.3139 \\
92.5 & 46 & 37 & 22 & 22.72155 & -0.72155 & 3.27978 \\
90 & 45 & 36 & 22 & 22.01791 & -0.01791 & 0.08139 \\
92.5 & 46 & 37 & 23 & 22.72155 & 0.278448 & 1.210642 \\
82.5 & 42 & 33 & 20 & 19.24964 & 0.750358 & 3.751792 \\
\hline
\end{tabular}

Şekil 8' de ise test verileri için günlük olarak ölçülen gerçek çĭ̆ noktası sicaklığı ve YSA ile tahmin edilen çiğ noktası sıcaklığı değerlerinin karşılaştırılmalı grafiği verilmiştir. Genel olarak gerçek ve tahmin edilen değerlerin birbirine oldukça yakın olduğu görülmektedir. 


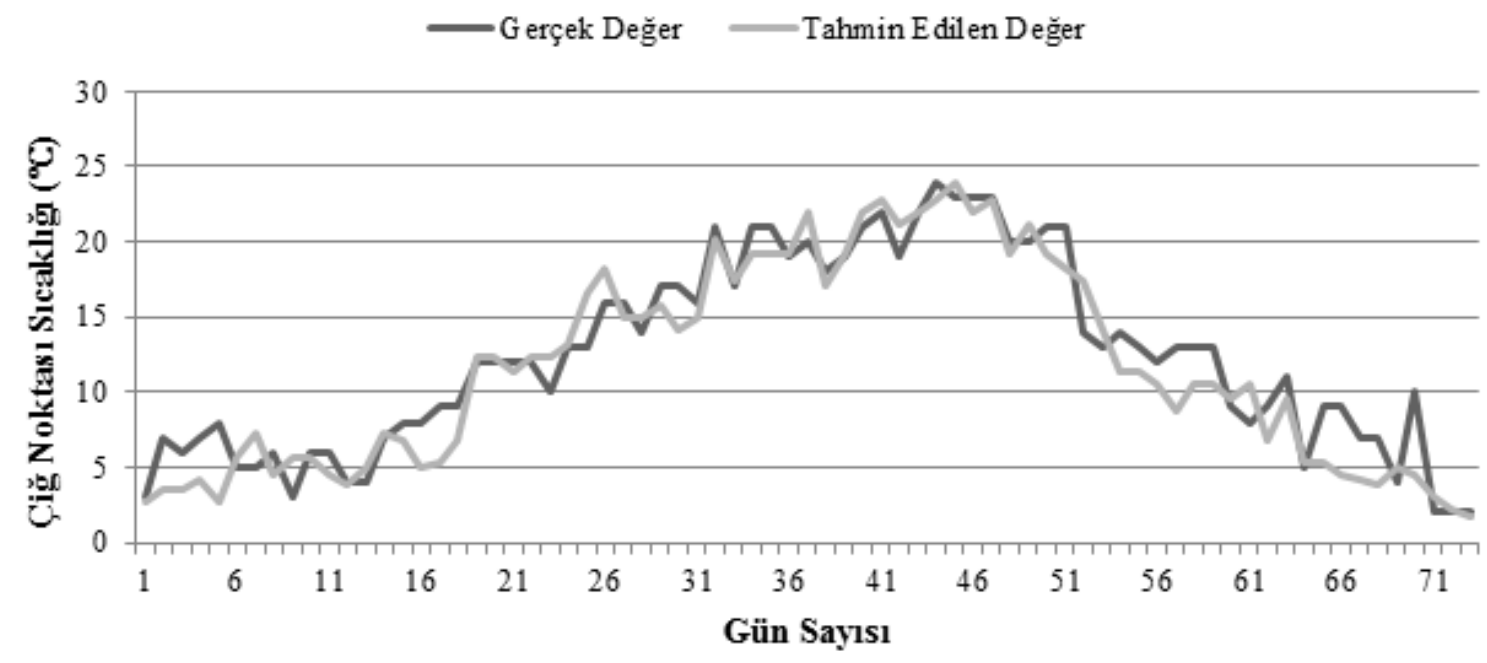

Şekil 8. Günlük olarak gerçek ve YSA ile tahmin edilen çiğ noktası sıcaklığı değerlerinin karşılaştırması

\section{Sonuçlar}

Seyrek yağış alan kurak bölgelerde ve seracılığın yoğun olduğu bölgelerde çiğ noktası sicaklı̆̆ tahmini önemli bir role sahiptir. Bu çalışmada çiğ noktası sıcaklığının belirlenmesi için yeni bir yaklaşım olarak YSA modeli kullanılmıştır. YSA metodu, Muğla ili için çiğ noktası sıcaklı̆̆ değerlerini belirlemek için uygulanmıştır. YSA metodu ile tahmin edilen değerler ile gerçek değerler karşılaştırılmıştır. İstatiksel analizler sonucunda RMSE hata değeri $2.112987863, \mathrm{R}^{2}$ değeri 0.887436814 , cov değişim katsayıs1 0.170439905 olarak bulunmuştur. Bu değerlerin kabul edilebilir seviyede olduğu görülmüştür. Ayrıca en büyük yüzde hata değeri \% 3.8 olarak bulunmuştur. Test verileri için günlük olarak ölçülen gerçek ve YSA ile tahmin edilen çiğ noktası sıcaklığı değerlerinin karşılaştırmalı grafikleri verilmiştir. Sonuç olarak, YSA modelinin çiğ noktası sıcaklığının tahmin edilmesinde başarıyla kullanılabileceği görülmüştür.

$\mathrm{Bu}$ çalışmada geliştirilen YSA modeli ile nem oranı, basınç ve hava sıcaklığ değerlerine bağlı olarak çiğ noktası sıcaklığ 1 kısa bir süre içinde tahmin edilebilmektedir. Bu çalışmadan elde edilen sonuçlar, Muğla ilinde seracılık için çiğlenmeyi önlemek ve bitki verimliliğini arttırmak için kullanılabilir. Ayrıca farklı bölgeler ve farklı meteorolojik parametreler için de YSA modelleri ile çiğ noktası sıcaklığını doğru bir şekilde tahmin edebilmek mümkün olabilmektedir. $\mathrm{Bu}$ tür tahminler, ekolojistler, meteorologlar, tarım üreticileri ve hava durumu verileriyle çalışan araştırmacılar için faydalı olacaktır.

\section{Kaynaklar}

Agam, N. and Berliner, P.R. (2006). Dew formation and water vapor adsorption in semi-arid environments - a review. Journal of Arid Environments, 65(4), 572-590. https://doi.org/10.1016/j.jaridenv.2005.09.004.

Akyüz, A., Kumaş, K., Ayan, M. ve Güngör, A. (2020). Antalya İli Meteorolojik Verileri Yardımıla Hava Sıcaklığının Yapay Sinir Ağları Metodu ile Tahmini. Gümüşhane Üniversitesi Fen Bilimleri Enstitüsü Dergisi, 10(1), 146-154. https://doi.org/10.17714/gumusfenbil.511481.

Alizamir, M., Kim, S., Kisi, O. and Zounemat-Kermani, M. (2020). Deep echo state network: a novel machine learning approach to model dew point temperature using meteorological variables. Hydrological Sciences Journal, 65(7), 11731190.

https://doi.org/10.1080/02626667.2020.1735639

Amirmojahedi, M., Mohammadi, K., Shamshirband, S., Danesh, A.S., Mostafaeipour, A. and Kamsin, A. (2016). A hybrid computational intelligence method for predicting dew point temperature. Environmental Earth Sciences, 75(5), 415. 10.1007/s12665-015-5135-7.

Aslay, F. ve Özen, Ü. (2013). Meteorolojik parametreler kullanılarak yapay sinir ağları ile toprak sıcaklığının tahmini. Politeknik Dergisi, 16(4), 139-145.

Ayvaz, E. (2012). Yapay Sinir Ağlarl ve Paralel Akışlı Isı Eşanjörlerinde Uygulanması. Yüksek Lisans Tezi, Karadeniz Teknik Üniversitesi Fen Bilimleri Enstitüsü, Trabzon.

Baghban, A., Bahadori, M., Rozyn, J., Lee, M., Abbas, A., Bahadori, A. and Rahimali, A. (2016). Estimation of air dew point temperature using computational intelligence schemes. Applied 
Thermal Engineering, 93, 1043-1052. https://doi.org/10.1016/j.applthermaleng.2015.1 0.056 .

Bayır, R. (2008). Yapay Zeka Teknikleri Dersi Ders Notlar1. Karabük Üniversitesi Elektronik ve Bilgisayar Eğitimi Bölümü.

Boyac1, S., Akyüz, A., Üstün, S., Baytorun, A.N. ve Güğercin, Ö. (2017). Seralarda yüksek sicaklıkların azaltılmasinda kullanılan yöntemler. Türkiye Tarımsal Araştırmalar Dergisi, 4(1), 89-95. https://doi.org/10.19159/tutad.300720.

Hubbard, K.G., Mahmood, R. and Carlson, C. (2003). Estimating daily dew point temperature for the northern Great Plains using maximum and minimum temperature. Agronomy Journal, 95(2), 323-328. https://doi.org/10.2134/agronj2003.3230.

İlkuçar, M., Kaya, A. ve Çifci, A. (2018). Mekanik Özelliklere Göre Ağaç Türlerinin Yapay Sinir Ağları ile Tahmini. Gümüşhane Üniversitesi Fen Bilimleri Enstitüsü Dergisi, 8(1), 75-83. https://doi.org/10.17714/gumusfenbil.310585.

Kaftan, İ. (2010). Batı Türkiye gravite ve deprem katalog verilerinin yapay sinir ağlart ile değerlendirilmesi. Doktora Tezi, Dokuz Eylül Üniversitesi Fen Bilimleri Enstitüsü, İzmir.

Kisi, O., Kim, S. and Shiri, J. (2013). Estimation of dew point temperature using neuro-fuzzy and neural network techniques. Theoretical and Applied Climatology, 114(3), 365-373. https://doi.org/10.1007/s00704-013-0845-9.

Köksal, E., (2011). Makina Elemanlarl Konstrüksiyonunda Çentik Faktörünün Yapay Sinir Ağları ile Hesaplanması. Yüksek Lisans Tezi, Gazi Üniversitesi Fen Bilimleri Enstitüsü, Ankara.

Mahmood, R. and Hubbard, K.G. (2005). Assessing bias in evapotranspiration and soil moisture estimates due to the use of modeled solar radiation and dew point temperature data. Agricultural and forest meteorology, 130(1-2), 71-84. https://doi.org/10.1016/j.agrformet.2005.02.004.

Mehdizadeh, S., Behmanesh, J. and Khalili, K. (2017). Application of gene expression programming to predict daily dew point temperature. Applied Thermal Engineering, 112, 1097-1107. https://doi.org/10.1016/j.applthermaleng.2016.1 0.181 .

MGM-Meteoroloji Genel Müdürlüğü (2020, 15 Kasım). Erişim adresi https://www.mgm.gov.tr/

Mohammadi, K., Shamshirband, S., Motamedi, S., Petković, D., Hashim, R. and Gocic, M. (2015).
Extreme learning machine based prediction of daily dew point temperature. Computers and Electronics in Agriculture, 117, 214-225. https://doi.org/10.1016/j.compag.2015.08.008.

Mohammadi, K., Shamshirband, S., Petković, D., Yee, L. and Mansor, Z. (2016). Using ANFIS for selection of more relevant parameters to predict dew point temperature. Applied Thermal Engineering, 96, 311-319. https://doi.org/10.1016/j.applthermaleng.2015.1 1.081 .

Naganna, S.R., Deka, P.C., Ghorbani, M.A., Biazar, S. M., Al-Ansari, N. and Yaseen, Z.M. (2019). Dew point temperature estimation: application of artificial intelligence model integrated with nature-inspired optimization algorithms. Water, 11(4), 742. https://doi.org/10.3390/w11040742.

Ozbek, A. (2016). Estimation of Moist Air Thermodynamic Properties using Artificial Neural Network. Çukurova Üniversitesi Mühendislik Mimarlık Fakültesi Dergisi, 31(1), 51-58.

Qasem, S.N., Samadianfard, S., Sadri Nahand, H., Mosavi, A., Shamshirband, S. and Chau, K. W. (2019). Estimating daily dew point temperature using machine learning algorithms. Water, 11(3), 582. https://doi.org/10.3390/w11030582.

Paulsen, G.M. (1994). High temperature responses of crop plants. Physiology and determination of crop yield, 365-389. https://doi.org/10.2134/1994.physiologyanddete rmination.c25.

Peşkircioğlu, M., Özaydın, K.A., Özpınar, H., Nadaroğlu, Y., Cankurtaran, G.A., Sabahaddin, Ü. ve Şimşek, O. (2016). Bitkilerin Sicağa ve Soğuğa Dayanıklılık Bölgelerinin Türkiye Ölçeğinde Coğrafi Bilgi Sistemleri ile Haritalanması. Tarla Bitkileri Merkez Araştırma Enstitüsü Dergisi, 11-25. https://doi.org/10.21566/tbmaed.85397.

Shank, D.B., Hoogenboom, G. and McClendon, R.W. (2008). Dewpoint temperature prediction using artificial neural networks. Journal of applied meteorology and climatology, 47(6), 1757-1769. https://doi.org/10.1175/2007JAMC1693.1.

Shiri, J., Kim, S. and Kisi, O. (2014). Estimation of daily dew point temperature using genetic programming and neural networks approaches. Hydrology Research, 45(2), 165-181. https://doi.org/10.2166/nh.2013.229.

Sri Sankari, G. and Valarmathi, D.A. (2017). Weather Forecasting with Back Propagation of Neural Network using MATLAB. International Journal of Scientific Research in Computer Science. 
Engineering and Information Technology, 2(2), 2456-3307.

Şahan, M. ve Okur, Y. (2016). Akdeniz bölgesine ait meteorolojik veriler kullanılarak yapay sinir ağları yardımıyla güneş enerjisinin tahmini. Süleyman Demirel Üniversitesi Fen Edebiyat Fakültesi Fen Dergisi, 11(1), 61-71.

Şencan, A. and Kalogirou, S.A. (2005). A new approach using artificial neural networks for determination of the thermodynamic properties of fluid couples. Energy Conversion and Management, 46(15-16), 2405-2418.

https://doi.org/10.1016/j.enconman.2004.11.007

Zounemat-Kermani, M. (2012). Hourly predictive Levenberg-Marquardt ANN and multi linear regression models for predicting of dew point temperature. Meteorology and Atmospheric Physics, 117(3-4), 181-192. https://doi.org/10.1007/s00703-012-0192-x. 